\title{
Encapsulation of the dual FLAP/mPEGS-1 inhibitor BRP-187 into acetalated dextran and PLGA nanoparticles improves its cellular bioactivity
}

\section{Blerina Shkodra-Pula}

Friedrich-Schiller-Universitat Jena

\section{Christian Kretzer}

Friedrich-Schiller-Universitat Jena

Paul M. Jordan

Friedrich-Schiller-Universitat Jena

\section{Paul Klemm}

Friedrich-Schiller-Universitat Jena

\section{Andreas Koeberle}

Friedrich-Schiller-Universitat Jena

\section{David Pretzel}

Friedrich-Schiller-Universitat Jena

\section{Erden Banoglu}

Gazi Universitesi

\section{Stefan Lorkowski}

Friedrich-Schiller-Universitat Jena

\section{Maria Wallert}

Friedrich-Schiller-Universitat Jena

\section{Stephanie Höppener}

Friedrich-Schiller-Universitat Jena

\section{Steffi Stumpf}

Friedrich-Schiller-Universitat Jena

\section{Antje Vollrath}

Friedrich-Schiller-Universitat Jena

\section{Stephanie Schubert}

Friedrich-Schiller-Universitat Jena

\section{Oliver Werz}

Friedrich-Schiller-Universitat Jena

Ulrich Schubert ( $\nabla$ ulrich.schubert@uni-jena.de )

Friedrich Schiller University Jena https://orcid.org/0000-0003-4978-4670 
Research

Keywords: Acetalated dextran, PLGA, nanoparticles, leukotriene biosynthesis, FLAP inhibitor, mPGES-1, dual inhibitor, BRP-187

Posted Date: March 3rd, 2020

DOI: https://doi.org/10.21203/rs.3.rs-15745/v1

License: (c) (i) This work is licensed under a Creative Commons Attribution 4.0 International License.

Read Full License 


\section{Abstract}

Background: Dual inhibitors of the 5-lipoxygenase-activating protein (FLAP) and the microsomal prostaglandin E2 synthase-1 (mPGES-1) may exert better anti-inflammatory efficacy and lower risks of adverse effects versus non-steroidal anti-inflammatory drugs. Despite these advantages, many dual FLAP/mPGES-1 inhibitors are acidic lipophilic molecules with low solubility and strong tendency for plasma protein binding that limit their bioavailability and bioactivity. Here, we present the encapsulation of the dual FLAP/mPGES-1 inhibitor BRP-187 into the biocompatible polymers acetalated dextran (Acdex) and poly(lactic-co-glycolic acid) (PLGA) via nanoprecipitation.

Results: The nanoparticles containing BRP-187 were prepared by the nanoprecipitation method and analyzed by dynamic light scattering regarding their hydrodynamic diameter, by scanning electron microscopy for morphology properties, and by UV-VIS spectroscopy for determination of the encapsulation efficiency of the drug. Moreover, we designed fluorescent BRP-187 particles, which showed high cellular uptake by leukocytes, as analyzed by flow cytometry. Finally, BRP-187 nanoparticles were tested in human polymorphonuclear leukocytes and macrophages to determine drug uptake, cytotoxicity, and efficiency to inhibit FLAP and mPGES-1.

Conclusion: Our results demonstrate that encapsulation of BRP-187 into Acdex and PLGA is feasible, and both PLGA- and Acdex-based particles loaded with BRP-187 are more efficient in suppressing

5-lipooxygenase product formation and prostaglandin E2 biosynthesis in intact cells as compared to the free compound, particularly after prolonged preincubation periods.

\section{Background}

Inflammation is a physiological reaction of the body to fight harmful invaders and to restore damaged tissue. However, if inflammation persists and the body cannot return to homeostasis, chronic inflammatory diseases such as arthritis, Alzheimer's disease or arteriosclerosis can evolve [1]. Inflammation is initialized and maintained by prostaglandins (PG) and leukotrienes (LT) that are biosynthesized from arachidonic acid (AA) [2]. For PG formation, AA is first converted by cyclooxygenase1 and $-2(\mathrm{COX}-1 / 2)$ to the intermediate prostaglandin $\mathrm{H}_{2}\left(\mathrm{PGH}_{2}\right)$, which is subsequently metabolized by specific $P G$ synthases into different bioactive prostanoids. Among them, prostaglandin $E_{2}\left(P E_{2}\right)$ is massively produced by microsomal prostaglandin $E_{2}$ synthase- 1 (mPGES-1) and is most relevant for inflammation, while other prostanoids (e.g. prostaglandin $\mathrm{I}_{2}$, thromboxane $\mathrm{A}_{2}$ ) are of importance for homeostatic processes, e.g., regulation of blood pressure and platelet aggregation [3]. Current antiinflammatory therapies include non-steroidal anti-inflammatory drugs (NSAIDs) that prevent inflammation by blocking PG biosynthesis via inhibition of COX-1/2. However, inhibition of COX enzymes is associated with side effects since the formation of all prostanoids is blocked and AA is preferably metabolized to pro-inflammatory LT [4]. The formation of LT from AA is initialized by 5-lipoxygenase (5- 
LO) together with 5-LO-activating protein (FLAP), with the latter facilitating access of 5-LO to AA [5]; both proteins are pursued as molecular targets in the development of anti-inflammatory drugs [6].

BRP-187 (4-(4-chlorophenyl)-5-[4-(quinoline-2-ylmethoxy)phenyl]isoxazol-3-carboxylic acid) is a dual

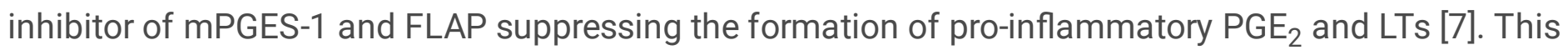
pharmacological approach is proposed to be more efficacious and associated with fewer adverse effects than inhibition of the COX pathway [8]. However, BRP-187 is an acidic lipophilic molecule with low water solubility and a strong tendency for plasma protein binding, implying the need for new technological approaches to overcome these disadvantages. Encapsulation of small molecule drugs that exhibit a low solubility into biodegradable polymers (polyesters or polyketals) can improve their bioavailability $[9,10]$. Here, we attempted to encapsulate BRP-187 into polymer-based nanoparticles (NPs) using poly(lactic-coglycolic acid) (PLGA) and acetalated dextran (Acdex). These polymers were selected because they are biocompatible materials able to successfully encapsulate hydrophobic drugs, and as such, they could facilitate an increase in the retention time of the drug in the plasma [11]. As a polyester, PLGA is enzymatically hydrolyzed into physiological metabolites - lactate and glycolate [12], hence, it is used and widely investigated as a biomaterial for drug delivery [13-15]. The properties of PLGA are influenced by the ratio of lactic to glycolic acid units, with a 50:50 composition showing the fastest degradation [16]. An alternative to PLGA is acetalated dextran (Acdex), a recently developed dextran derivative offering favorable properties as carrier for drugs with low solubility [17]. Acdex is composed of acyclic and cyclic acetal groups, with the acyclic acetals degrading faster than the cyclic acetal groups [17]. As a consequence, the degradation behavior of Acdex can be fine-tuned by varying the degree of substitution of the cyclic vs. acyclic acetal groups on the dextran backbone [18]. Most importantly, under slightly acidic conditions (e.g. pH 5.5), the acetal groups are cleaved, resulting in biocompatible, water-soluble dextran while instantly releasing the cargo [19]. In brief, the main advantage of Acdex lies in its facile synthesis (i), in the possibility to design formulations with a desired release profile by varying the cyclic vs. acyclic acetal groups in the dextran backbone (ii), and in its sensitivity to low pH levels - typical conditions of inflamed tissues and endosomal compartments [20]. In this view, both polymer formulations are intended for parenteral administration, with Acdex being suitable as an instant-release formulation, whereas PLGA might be suitable for extended-release formulations. In addition, based on the longer degradation time of the PLGA NPs in tissue ( $>40$ days), depot formulations for local administration routes (e.g. intra-muscular or intra-articular for rheumatoid arthritis) could also be considered.

In this study, formulations of BRP-187-containing NPs of 130 to $230 \mathrm{~nm}$ using Acdex and PLGA as biodegradable encapsulating materials were prepared. The properties of these NPs were analyzed including the degradation behavior, and the FLAP/mPGES-1-inhibitory efficiency of BRP-187-containing NPs was evaluated in comparison to the free compound in different human primary leukocytes.

\section{Results And Discussion}


The formulation parameters were designed to produce stable monodisperse particles of 100 to $200 \mathrm{~nm}$ and with high drug loading. The excipients used in the formulation were selected after careful consideration based on previous data from our lab, literature, and most importantly based on the technical requirements of the International Council for Harmonization (ICH) guidelines for pharmaceuticals for human use. Acetone was used as organic phase for the following reasons: It is a good solvent for both polymers (i); it is miscible with water, which is a pre-requisite for solvents used in nanoprecipitation (ii) [21]; it can be easily removed from the formulation by evaporation at room temperature (iii); and according to the $\mathrm{ICH}$, acetone is a Class 3 solvent with a low toxicity [22]. Next, for the solubilization of the drug, due to the high lipophilicity of BRP-187, the choice of the solvent was limited only to dimethylsulfoxide (DMSO) and dimethylformamide (DMF). Thus, considering that DMF is more toxic than DMSO (residual concentration limit 880 ppm vs. 5000 ppm, respectively), the latter was selected for the formulation [22]. Meanwhile, the residual amount of DMSO in our NP formulations was < $250 \mathrm{ppm}$. Furthermore, the volumetric ratio of organic-to-aqueous phase was kept at 1:8 to produce particles $<200 \mathrm{~nm}$ with an encapsulation efficiency EE $>50 \%$, higher volumetric ratios produce NPs > $200 \mathrm{~nm}$ [23]. Partially-hydrolyzed poly(vinyl alcohol) (PVA) was used as surfactant and cryoprotectant to prevent aggregation during purification and lyophilization, respectively. We have previously demonstrated that PVA provided a superior stability of PLGA NPs than poloxamers and polysorbates at concentrations $<0.5 \%$, and no toxicity was evident even at 100 -fold higher concentrations [10].

\subsection{Characterization of NPs}

Initial experiments revealed that NPs prepared by the nanoprecipitation method had a higher EE than NPs prepared by the emulsion-evaporation method. In addition, the nanoprecipitation method is favored because it is a low-energy method with an easy operation that can be easily adapted to large-scale production batches [24]. The size and polydispersity (PDI) of BRP-187-loaded NPs as well as unloaded control NPs were analyzed after purification and after lyophilization, and the zeta potential (ろ) was measured after lyophilization (Table 1$)$. The average hydrodynamic diameter $\left(\mathrm{d}_{\mathrm{H}}\right)$ of the final NPs was between 130 to $211 \mathrm{~nm}$ with PDI values of 0.09 to 0.28 . PLGA NPs were in average up to $50 \mathrm{~nm}$ smaller than Acdex NPs. 
Table 1

Overview of the NP properties.

\begin{tabular}{|c|c|c|c|c|c|c|c|c|}
\hline \multirow[t]{2}{*}{ NP formulation } & \multicolumn{2}{|c|}{ After purification } & \multicolumn{3}{|c|}{ After lyophilization } & \multirow{2}{*}{$\begin{array}{l}\text { EE } \\
\text { [\%] }\end{array}$} & \multirow[t]{2}{*}{ LC [\%] } & \multirow[t]{2}{*}{ PVA [\%] } \\
\hline & $\begin{array}{l}\mathrm{d}_{\mathrm{H}} \\
{[\mathrm{nm}]}\end{array}$ & PDI & $\begin{array}{l}d_{H} \\
{[n m]}\end{array}$ & PDI & $\begin{array}{l}\zeta \\
{[\mathrm{mV}]}\end{array}$ & & & \\
\hline Acdex & $\begin{array}{l}210 \pm \\
26\end{array}$ & $\begin{array}{l}0.17 \pm \\
0.07\end{array}$ & $\begin{array}{l}211 \pm \\
35\end{array}$ & $\begin{array}{l}0.26 \pm \\
0.09\end{array}$ & $\begin{array}{l}-12 \\
\pm 2\end{array}$ & I & / & $\begin{array}{l}0.01 \pm \\
0.000\end{array}$ \\
\hline Acdex[BRP-187] & $\begin{array}{l}196 \pm \\
51\end{array}$ & $\begin{array}{l}0.16 \pm \\
0.11\end{array}$ & $\begin{array}{l}178 \pm \\
26\end{array}$ & $\begin{array}{l}0.13 \pm \\
0.07\end{array}$ & $\begin{array}{l}-13 \\
\pm 8\end{array}$ & $\begin{array}{l}59 \pm \\
23\end{array}$ & $\begin{array}{l}1.7 \pm \\
0.6\end{array}$ & $\begin{array}{l}0.01 \pm \\
0.000\end{array}$ \\
\hline $\begin{array}{l}\text { Acdex- } \\
\text { RhodB[BRP-187] }\end{array}$ & $\begin{array}{l}163 \pm \\
15\end{array}$ & $\begin{array}{l}0.20 \pm \\
0.06\end{array}$ & $\begin{array}{l}189 \pm \\
37\end{array}$ & $\begin{array}{l}0.28 \pm \\
0.11\end{array}$ & $\begin{array}{l}-24 \\
\pm 2\end{array}$ & $\begin{array}{l}67 \pm \\
10\end{array}$ & $\begin{array}{l}2.0 \pm \\
0.3\end{array}$ & n.m. \\
\hline PLGA & $\begin{array}{l}124 \pm \\
6\end{array}$ & $\begin{array}{l}0.06 \pm \\
0.03\end{array}$ & $\begin{array}{l}130 \pm \\
2\end{array}$ & $\begin{array}{l}0.09 \pm \\
0.03\end{array}$ & $\begin{array}{l}-20 \\
\pm 2\end{array}$ & I & l & $\begin{array}{l}0.02 \pm \\
0.002\end{array}$ \\
\hline PLGA[BRP-187] & $\begin{array}{l}153 \pm \\
41\end{array}$ & $\begin{array}{l}0.17 \pm \\
0.14\end{array}$ & $\begin{array}{l}158 \pm \\
35\end{array}$ & $\begin{array}{l}0.12 \pm \\
0.06\end{array}$ & $\begin{array}{l}-15 \\
\pm 3\end{array}$ & $\begin{array}{l}76 \pm \\
22\end{array}$ & $\begin{array}{l}2.2 \pm \\
0.6\end{array}$ & $\begin{array}{l}0.03 \pm \\
0.002\end{array}$ \\
\hline PLGA-DY635 & $\begin{array}{l}143 \pm \\
3\end{array}$ & $\begin{array}{l}0.08 \pm \\
0.03\end{array}$ & $\begin{array}{l}154 \pm \\
5\end{array}$ & $\begin{array}{l}0.15 \pm \\
0.02\end{array}$ & $\begin{array}{l}-20 \\
\pm 1\end{array}$ & I & / & $\begin{array}{l}0.02 \pm \\
0.006\end{array}$ \\
\hline $\begin{array}{l}\text { PLGA-DY635[BRP- } \\
\text { 187] }\end{array}$ & $\begin{array}{l}153 \pm \\
2\end{array}$ & $\begin{array}{l}0.12 \pm \\
0.01\end{array}$ & $\begin{array}{l}168 \pm \\
9\end{array}$ & $\begin{array}{l}0.19 \pm \\
0.05\end{array}$ & $\begin{array}{l}-19 \\
\pm 1\end{array}$ & $\begin{array}{l}87 \pm \\
6\end{array}$ & $\begin{array}{l}2.5 \pm \\
0.2\end{array}$ & $\begin{array}{l}0.02 \pm \\
0.002\end{array}$ \\
\hline $\begin{array}{l}\mathrm{d}_{\mathrm{H}}=\text { Hydrodynamic } \\
\text { loading capacity. } \mathrm{C} \\
\text { measurements } \mathrm{n} \geq\end{array}$ & $\begin{array}{l}\text { diamete } \\
\text { ncentrat }\end{array}$ & btained $\mathrm{k}$ & $\begin{array}{l}\text { LS me } \\
\text { ed for th }\end{array}$ & urement & $E=$ enc & psulati & $\begin{array}{l}\text { efficien } \\
\text { D for al }\end{array}$ & LC $=$ \\
\hline
\end{tabular}

SEM imaging showed a spherical morphology of the NPs and smaller NP sizes compared to the results acquired by DLS, a common phenomenon when using orthogonal characterization techniques (Fig. 1) [25]. The size of the NPs measured by SEM was as follows: Acdex $95 \pm 11 \mathrm{~nm}$, Acdex[BRP-187] $73 \pm 8 \mathrm{~nm}$, PLGA $96 \pm 11 \mathrm{~nm}$, and PLGA[BRP-187] $84 \pm 6 \mathrm{~nm}$. Furthermore, EE of all NPs is given in Table 1 and was roughly $60 \%$ for Acdex particles and $80 \%$ for PLGA particles. Based on previous experiments, a drug-topolymer content $>3 \%(\mathrm{w} / \mathrm{w})$ fed in the formulation resulted in problems with the stability of the suspension (data not shown), a phenomenon that was also reported by others [26-28]. Meanwhile, the conditions used in this protocol $(3 \%, \mathrm{w} / \mathrm{w})$ were effective to encapsulate more than $60 \%$ of the drug without compromising the stability of the NPs. In addition, BRP-187 is a highly potent drug $\left(\mathrm{IC}_{50 \text { (FLAP) }}=\right.$ $8 \mathrm{nM}$ and $\mathrm{IC}_{50 \text { (mPGES-1) }}=200 \mathrm{nM}$ ) [7], and a loading capacity of 1.7 to $2.5 \%$ corresponded to 37 to $55 \mu \mathrm{M}$ of BRP-187 in $1 \mathrm{mg} \mathrm{mL}^{-1} \mathrm{NP}$ suspension. Here, it was observed that Acdex formed larger particles but encapsulated less drug compared to PLGA, which is probably due to different drug-polymer interactions [26].

\subsection{Degradation profile of the nanoparticles}


In DLS, the count rate corresponds to the number of the light photons detected in kilo-count per seconds (kcps), which is a good indicator of the quality of the measured sample [29]. A decreasing count rate indicates that less photons are detected (i.e. less light is scattered) [29] and, thus, less particles are present in a sample. In such a measurement, the NPs should show stable size and PDI values $(100 \%$ intact NPs) at time point 0 of NPs incubated with buffer (Fig. 2A and C). As the NPs start to degrade, they steadily increase in size and polydispersity, which is a result of the degraded products dissolved in water (Fig. 2B and D). Consequently, the count rate decreases over time as the degradation of the NPs proceeds.

The release of a molecule from a NP polymer matrix depends on several factors, i.e. the structure-property relationship between the drug and the polymer, hydrophobicity of the drug and the polymer, as well as the degradation rate, melting point and crystallinity of the polymer [30]. The degradation rate of the polymeric

NPs in a cell-free environment was studied since it directly influences the release kinetics of the drug from the NP core. According to the literature, Acdex is an acid-labile polymer with a considerably higher $\mathrm{pH}$ sensitivity compared to the PLGA polymer $[17,31]$. Our results revealed that after

$10 \mathrm{~h}$ of incubation Acdex NPs exhibit good stability at pH 7.4 showing only swelling of the NPs, whereas at the same $\mathrm{pH}$ value the Acdex[BRP-187] NPs degraded to a degree of about $25 \%$. Furthermore, at $\mathrm{pH} 4.8$ after 50 min, the Acdex NPs degraded by only about 30\%, whereas the Acdex[BRP-187] NPs degraded by $75 \%$ (Fig. 2A). This degradation behavior is suitable since NPs maintain $75 \%$ stability at physiological conditions. However, once internalized by the cells, the acidic environment of the endolysosome would trigger the degradation of Acdex, thereby releasing the drug. In case of PLGA, a complete degradation of NPs was observed at $\mathrm{pH} 4.8$ within 40 days, whereas at $\mathrm{pH} 7.4$, an $80 \%$ degradation was observed after 60 days (Fig. 2C), which is in line with previous studies [32-34]. Considering the degradation profile of the polymers in an acidic medium, the release of BRP-187 from Acdex NPs is expected to be fast due to the rapid degradation of the polymer, whereas the drug release from PLGA NPs is expected to be slower due to the diffusion of drug from the polymer matrix, since degradation of this polymer is very slow [35]. The degradation studies of the NPs at different $\mathrm{pH}$ values were investigated to obtain a first impression on the release of the drug from the NPs. However, it should be noted that such degradation profiles differ from the more complex environment of the endolysosomes [36].

\subsection{Residual amount of PVA}

Previously, we described effects of surfactants on the stability of drug-loaded NPs, where we demonstrated that concentrations of $\leq 1 \%(\mathrm{w} / \mathrm{v})$ PVA are desirable to formulate stable particles [10]. Here, we formulated NPs using $0.3 \%$ (w/v) PVA to obtain both suspension- and cryo-stability. The amount of residual PVA in the final NPs is listed in Table 1. The enzymatic- and pH-dependent degradation of the NPs relies not only on the properties of the polymer itself but is also strongly influenced by the digestibility of the surfactant. PVA coating can protect from enzymatic hydrolysis of the NPs by decreasing the wettability of the NPs [37], thus influencing the rate of degradation and drug release.

\subsection{Fluorescence dye-labeled nanoparticle uptake in PMNL}


PMNL are pro-inflammatory innate immune cells that are abundant in the blood and produce substantial amounts of LTs and also PGE 2 as targets for BRP-187 [7, 38]. Therefore, we used human PMNL as relevant cells to study the uptake of BRP-187-loaded NPs that were covalently labeled with fluorescent dyes (i.e., PLGA-DY635, Acdex-RhodB) for visualization in the cells. The dye-labeled NPs (loaded with BRP187) were efficiently taken up by PMNL, which depends however on the nature of the polymer, being superior for PLGA over Acdex (Fig. 3). Within $10 \mathrm{~min}, 40 \%$ of the PMNL digested PLGA-DY635[BRP-187] NPs. After 180 min, approx. $85 \%$ of the PMNL took up these NPs along with a concomitant increase of the mean fluorescence intensity (MFI) per PMNL up to $1937 \pm 283$. Thus, PLGA NPs display an excellent cellular uptake. In contrast, Acdex-RhoB[BRP-187] NPs were taken up by only $23 \%$ of the PMNL after $120 \mathrm{~min}$, with an even slightly lower uptake after $180 \mathrm{~min}$, correlating with the MFI per cell over the entire time course (Fig. 3). According to the degradation profile of Acdex NPs (Fig. 2), the lower abundance might be a consequence of the concomitant degradation and elimination of the polymer inside the cell. After $2 \mathrm{~h}$, the Acdex NPs are mostly degraded at the endolysosomal pH of approx. 4.8. Therefore, the fluorescence signal may not increase further, even though NPs are still taken up, because the elimination of the labeled monomers from the cell is ongoing. However, both PLGA- and Acdex-based NPs are rapidly taken up by PMNL, even though PLGA NPs are ingested by a higher fraction of cells as compared to Acdex NPs. Additionally, we used confocal laser scanning microscopy to confirm the cellular internalization of NPs into PMNL (Fig. 4). PLGA-DY635[BRP-187] NPs show a time-dependent accumulation within the cells which appears as an increase of the intracellular fluorescence signal over time that is most prominent after $3 \mathrm{~h}$. For Acdex-RhoB[BRP-187] NPs a comparable signal was already observed after $30 \mathrm{~min}$. Remarkably, the NP-uptake after $30 \mathrm{~min}$, as measured by the corresponding fluorescence intensity signal, does not further increase upon longer incubation up to $3 \mathrm{~h}$.

\subsection{Encapsulation of BRP-187 into PLGA or Acdex NPs is not detrimental for target cells}

Next, we evaluated whether or not the NPs may cause detrimental effects upon long-term incubation ( $\geq$ $24 \mathrm{~h}$ ) towards relevant target cells. Since PMNL are short-lived cells upon isolation being not suitable for long-term cytotoxicity tests, human monocyte-derived macrophages were used since they also possess the capability to produce PGE ${ }_{2}$ and LT [39]. None of the NP formulations (nor free BRP-187) showed detrimental effects on the viability of macrophages (with M1 or M2 phenotype) in terms of damage of the cell membrane over $24 \mathrm{~h}$ as measured by LDH assay (Fig. 5). In supportive experiments using a RAW264.7 macrophage cell line that was incubated for $72 \mathrm{~h}$ with the NPs, an MTT assay revealed also no significant cytotoxic effects (data not shown). Thus, the NPs exert no detrimental effects against relevant target cells at concentrations used in functional assays.

\subsection{Effect of encapsulated BRP-187 on 5-LO product formation in PMNL}


BRP-187 $(1 \mu \mathrm{M})$ efficiently suppressed 5-LO product formation in isolated PMNL upon short preincubation periods $\leq 2 \mathrm{~h}$ (Fig. 6A,B,C), which is in agreement with our previous data [7]. However, after prolonged preincubation $(5 \mathrm{~h})$ with PMNL, the efficiency of BRP-187 $(1 \mu \mathrm{M})$ was clearly reduced and suppression of 5 -LO product formation was only $37 \pm 5 \%$ of the control (Fig. $6 \mathrm{D})$. Of interest, BRP-187 encapsulated into PLGA or Acdex NPs (corresponding to $1 \mu \mathrm{M}$ BRP-187 as well) potently and consistently inhibited 5-LO product formation in PMNL by 80 to $92 \%$, even after a preincubation period of $5 \mathrm{~h}$. Note that NPs devoid of BRP-187 did not suppress 5-LO activity in PMNL. Therefore, we conclude that encapsulation of BRP-187 into PLGA or Acdex NPs generally accomplishes efficient inhibition of 5-LO product formation in PMNL, and, moreover, allows to overcome the loss of potency of BRP-187 upon prolonged exposure (i.e. $5 \mathrm{~h}$ ) of PMNL.

\subsection{Effect of encapsulated BRP-187 on $\mathrm{PGE}_{2}$ formation in human M1 macrophages}

Human M1 macrophages express high levels of mPGES-1 [40] and, upon exposure to pathogenic E. coli, produce high amounts of pro-inflammatory $\mathrm{PGE}_{2}$ [39]. Thus, E. coli-stimulated $\mathrm{M} 1$ macrophages are a suitable cell model to study the efficiency of mPGES-1 inhibitors. Note that many mPGES-1 inhibitors are highly potent in cell-free assays but markedly loose efficiency in cellular assays or in vivo [41], which necessitates technological approaches to overcome these hurdles. BRP-187 potently inhibited mPGES-1 in a cell-free assay $\left(\mathrm{IC}_{50}=0.2 \mu \mathrm{M}\right)[7]$, however, pretreatment of human $\mathrm{M} 1$ with $1 \mu \mathrm{M}$ BRP-187 caused only moderate inhibition (30-37\%) of E. coli-induced $\mathrm{PGE}_{2}$ formation regardless of the preincubation period (15 min, 5 or $20 \mathrm{~h}$ ). In our study, encapsulation of BRP-187 into PLGA NPs strongly suppressed $\mathrm{PGE}_{2}$ levels at short (15 min) and prolonged (20 h) preincubation periods (Fig. 7). Also, Acdex [BRP-187] NPs caused strong reduction of $\mathrm{PGE}_{2}$ formation when $\mathrm{M} 1$ were preincubated for $20 \mathrm{~h}$, while $15 \mathrm{~min}$ pretreatment was not effective. These data are in line with the cellular uptake pattern of the NPs, where PLGA NPs surpassed the uptake efficiency of Acdex NPs. Note that again, as for 5-LO product formation in PMNL, the empty NPs did not suppress $\mathrm{PGE}_{2}$ biosynthesis.

In summary, encapsulation of BRP-187 in PLGA and Acdex NPs overcomes the loss of effectiveness against mPGES-1 in intact cells versus cell-free assay conditions and confers the drug marked potency, highlighting this technological approach for efficient interference with pro-inflammatory $\mathrm{PGE}_{2}$ and LT formation in human cells. The beneficial effect of encapsulation of BRP-187 especially after prolonged incubations up to $20 \mathrm{~h}$ might be related to better stability and delayed release inside the cell. Intriguingly, encapsulation of BRP-187, particularly in PLGA-based NPs, accomplished efficient mPGES-1 inhibition in intact M1 macrophages, which was not the case for the free drug. It is conceivable that PLGA is cleaved in close proximity to the endoplasmic reticulum where mPGES-1 is located, thus, enabling unhindered access of BRP-187 to its target protein without being bound to other cellular membranes or cell compartments. 


\section{Conclusion}

Encapsulation of BRP-187 into polymer-based NPs improves the potency and duration of bioactivity of the drug in relevant human primary leukocytes compared to the free drug. PLGA and Acdex were chosen as biocompatible matrix polymers. Both polymers enabled stable formulations of BRP-187-loaded NPs with a monodisperse size distribution in the range of $200 \mathrm{~nm}$ and high EE according to a highly reproducible encapsulation method. It was shown that PLGA and Acdex NPs remained stable at physiological blood $\mathrm{pH}$, whereas at $\mathrm{pH} 4.8$, Acdex particles degraded very fast after $1 \mathrm{~h}$, which indicates that they are biodegradable in the cellular endolysosome after they have been taken up via phagocytosis by PMNL or macrophages. According to the cellular uptake data, both kind of NPs are internalized by PMNL and started to degrade, leading to the release of BRP-187 inside the cell, though the uptake of PLGA NPs is faster and more efficient than Acdex NPs. Most importantly, both PLGA- and Acdex-based NPs loaded with BRP-187 are more efficient in suppressing 5-LO product formation and PGE 2 biosynthesis in intact cells as compared to the free compound, particularly after prolonged preincubation periods. When isolated leukocytes were preincubated with BRP-187 for typical short-term periods, the compound was highly bioactive against FLAP [7], but prolonged exposure for more than $2 \mathrm{~h}$ markedly decreased the potency of BRP-187. Notably, encapsulation of BRP-187 in Acdex- and PLGA particles accomplishes efficient mPGES-1 inhibition in M1 macrophages, which is a major step forward in the development of mPGES-1 inhibitors in general, since many mPGES-1 inhibitors fail in intact cells.

In view of the potential use of BRP-187 as drug for therapeutic treatment of chronic inflammatory diseases, the prolongation of its bioactivity is of utmost importance. An efficient encapsulation and release of BRP-187 is a promising approach to reach this aim. As a perspective, other biodegradable polymers for encapsulation of BRP-187 might be evaluated, and in addition to the properties reported here, further aspects of the nanoformulations (e.g. hydrophobicity, crystallinity and protein corona) might be assessed in more detail. It will also be challenging to study the effects of encapsulated BRP-187 in animal models of inflammation related to $\mathrm{PGE}_{2}$ and $\mathrm{LTs}$ in the future. In such physiological environment, the various aspects of bioavailability including distribution in other tissues and influence of plasma proteins may be assessed.

\section{Methods}

\subsection{Materials}

Poly(D,L-lactic-co-glycolic) acid (Resomer RG 502 H, copolymer composition of 50:50, 7-17 kDa, acid terminated) was purchased from Evonik Industries (Germany). Partially hydrolyzed PVA (Mowiol 4-88), acetone $(>99 \%$ ) and dimethyl sulfoxide (DMSO $>99 \%$, spectroscopic grade) were all purchased from Sigma-Aldrich (Germany). The dye DY635 was purchased from Dyomics (Jena, Germany). The covalent coupling of PLGA polymer with the dye DY635 amine was performed according to a standard procedure with 1-ethyl-3-(3-dimethylaminopropyl)carbodiimide (EDC) and N-hydroxysuccinimide (NHS) and was provided by SmartDyeLivery (Jena, Germany). The acetalation of dextran was done according to an 
adapted procedure (Mw of parent dextran $60 \mathrm{kDa}$ ), degree of substitution (DS) 2.97 (DS cyclic acetal $_{\text {1 }}=1.98$, DS acyclic acetal 0.99) [19]. BRP-187 was synthesized according to an established protocol [42].

Deuterated and non-deuterated lipid mediator standards for UPLC-MS-MS quantification were purchased from Cayman Chemical/Biomol (Germany). For further materials, see specific experimental section.

\subsection{Acdex-rhodamine B synthesis}

Rhodamine B was coupled to Acdex (Mw 9 to $11 \mathrm{kDa}$, Sigma Aldrich) according to an adapted procedure [43]: $1 \mathrm{~g}$ Acdex (6.17 mmol anhydroglucose unit, $\left.D S_{\text {acyclic acteal }}=0.56, D_{\text {cyclic acetal }}=2.14\right)$ and $13 \mathrm{mg}$ rhodamine $B$ isothiocyanate were dissolved in $15 \mathrm{~mL}$ anhydrous pyridine and heated to $80{ }^{\circ} \mathrm{C}$ for $72 \mathrm{~h}$ under argon. The reaction mixture was precipitated in $150 \mathrm{~mL}$ distilled water, and centrifuged; the pellet was lyophilized. The resulting pink-colored powder was purified via gel permeation chromatography using BioBeads S-X1 in tetrahydrofuran (THF) to remove the free dye (yield $57 \%$ ). Size-exclusion chromatography was performed in dimethylacetamide (DMAC) and $0.21 \%$ lithium chloride with a UV-VIS detector measuring at $\lambda=562 \mathrm{~nm}$ to prove the conjugation of the dye to the polymer.

\subsection{Nanoparticle formulation}

Particles were prepared by nanoprecipitation using a syringe pump (Aladdin AL1000-220, World Precision Instruments, Berlin, Germany) with a flow rate of $2 \mathrm{~mL} \mathrm{~min}^{-1}$. First, $25 \mathrm{mg}$ polymer (Acdex or PLGA) were dissolved in $5 \mathrm{~mL}$ acetone. For the drug solution, a $10 \mathrm{mg} \mathrm{mL}^{-1}$ stock of BRP-187 in DMSO was prepared and sonicated in an ultrasound bath for $15 \mathrm{~min}$ at room temperature. Subsequently, $75 \mu \mathrm{L}$ of the drug solution were mixed with the polymer solution. For the aqueous phase, $40 \mathrm{~mL}$ of $0.3 \%(\mathrm{w} / \mathrm{v})$ PVA solution were prepared. Further, the polymer (or polymer-drug) solution was injected into the aqueous solution, while stirring at $800 \mathrm{rpm}$ at room temperature. After nanoprecipitation, the samples were stirred for $24 \mathrm{~h}$ in a fume hood to evaporate the acetone. The particles were washed once, using a Rotina $380 \mathrm{R}$ centrifuge (Hettich Lab Technology, Germany) at $12.851 \times \mathrm{g}$ for $60 \mathrm{~min}$ at $20^{\circ} \mathrm{C}$. After removing the supernatant, NPs were redispersed in $2.5 \mathrm{~mL}$ pure water, vortexed 5 to $10 \mathrm{sec}$ and then sonicated in an ultrasound bath for $30 \mathrm{~min}$. For the Acdex NPs, $100 \mu \mathrm{L}$ of $0.01 \%$ triethylamine (TEA) of pH 9 were added to the suspension. The NPs were stored at $4{ }^{\circ} \mathrm{C}$ overnight to allow complete dispersion in water. The concentration of the particle dispersions was determined by freeze-drying up to six aliquots of 100 or $200 \mu \mathrm{L}$ NPs dispersion. The mass of the NPs was accurately weighed (Radwag Waagen, MYA 11.4Y, Germany) and an average was calculated for the NPs concentration.

\subsection{Dynamic light scattering (DLS)}

The size, polydispersity index and the zeta-potential of the particles was measured using a Zetasizer Nano ZS with a laser wavelength of $\lambda=633 \mathrm{~nm}$ (Malvern Instruments, Germany). The measurements were performed at $173^{\circ}$ backscatter angle with the following settings: Five repeated measurements at $25^{\circ} \mathrm{C}$, each measurement with five runs of $30 \mathrm{sec}$ and a $30 \mathrm{sec}$ equilibration time. The zeta-potential of the lyophilized NPs was measured at $25^{\circ} \mathrm{C}$ with three repeated measurements. The NPs were characterized after purification (10 $\mu \mathrm{L}$ NP dispersion diluted in $1 \mathrm{~mL}$ pure water), and after lyophilization 
(100 $\mu \mathrm{L}$ of NP dispersion were lyophilized and redispersed in $1 \mathrm{~mL}$ pure water). The intensity size distribution is reported as the hydrodynamic diameter $\left(d_{H}\right)$ of the NPs.

The degradation behavior of Acdex and PLGA NPs was determined by monitoring the mean count rate (kcps). The NP samples were measured using fixed settings $\left(37^{\circ} \mathrm{C}\right.$, measurement position 4.65 , and attenuator 7). The Acdex NPs were measured for $15 \mathrm{~h}: 180$ measurements (delay between measurements $240 \mathrm{sec}$ ), where each measurement consisted of three runs with $20 \mathrm{sec}$ run durations. The PLGA NPs were measured every day over a period of 60 days: Five measurements (with no delay between measurements), where each measurement consisted of one run with $30 \mathrm{sec}$ run duration.

\subsection{UV-VIS spectroscopy}

For the calculating the encapsulation efficiency (EE) and loading capacity (LC) of the drug in the NPs, aliquots of $200 \mu \mathrm{L}$ of the washed NPs dispersion were lyophilized. The dry NPs powder was dissolved in $200 \mu \mathrm{L}$ DMSO (spectroscopic grade). The polymer-drug solution was measured at $\lambda=316 \mathrm{~nm}$ with $3 \times 3$ multiple reads per well and $2000 \mu \mathrm{m}$ well border using the Infinite M200 Pro platereader (Tecan Group, Switzerland). For all EE measurements, a Hellma Quartz flat-transparent plate with 96 wells was used. A calibration curve of BRP-187 was obtained for each batch in the concentration range of 0.24 to $250 \mu \mathrm{g}$ $\mathrm{mL}^{-1}$ with $\mathrm{R}^{2}=0.9997$. Equations 1 and 2 were used to calculate $\mathrm{EE}$ and $\mathrm{LC}$ :

Equation $1 \quad L C=\frac{\text { mass of drug recovered }}{\text { mass of particle recovered }} \times 100$

Equation $2 \quad E E=\frac{L C}{L C \text { theoretical }} \times 100$

\subsection{PVA assay}

Determination of PVA in the NPs $(\%, w / w)$ was performed using UV-VIS spectroscopy. PVA forms a complex with iodine, which absorbs light at $\lambda=650$ to $690 \mathrm{~nm}$. In an adapted protocol, Lugol solution was used as iodine source [44]. Lyophilized NPs were redispersed in pure water $\left(3 \mathrm{mg} \mathrm{mL}^{-1}\right)$ and $90 \mu \mathrm{L}$ were pipetted into a 96-well plate. Then, $20 \mu \mathrm{L}$ of $1 \mathrm{M}$ sodium hydroxide was added to each NPcontaining well, and the solutions were mixed for $15 \mathrm{~min}$ at $850 \mathrm{rpm}$ at room temperature. Next, $20 \mu \mathrm{L}$ $1 \mathrm{M}$ hydrochloric acid, $60 \mu \mathrm{L} 0.65 \mathrm{M}$ boric acid and $10 \mu \mathrm{L}$ of Lugol solution were added to each well. Measurements on the plate reader were done at $\lambda=650 \mathrm{~nm} 15 \mathrm{~min}$ after the addition of the Lugol solution. The experiments were repeated three times for each NP formulation.

\subsection{Scanning electron microscopy (SEM)}

Electron microscopy imaging was performed with a Sigma VP Field Emission Scanning Electron Microscope (Carl-Zeiss, Jena, Germany) using an InLens detector with an accelerating voltage of $6 \mathrm{kV}$. The samples were coated with a thin layer of platinum $(4 \mathrm{~nm})$ via sputter coating (CCU-010 HV, Safematic, Switzerland) before the measurement. ImageJ was used to measure the particle sizes from 
the images acquired by the SEM, where a mean diameter was deduced by measuring 150 to 200 NPs/image.

\subsection{Degradation study}

The degradation behavior of loaded and unloaded NPs was tested at $37^{\circ} \mathrm{C}$ in $0.05 \mathrm{M}$ Tris- $\mathrm{HCl}$ buffer of $\mathrm{pH} 7.4$ and $0.05 \mathrm{M}$ acetate buffer of $\mathrm{pH}$ 4.8. Lyophilized NPs were dispersed in pure water (concentration of 3 to $7 \mathrm{mg} \mathrm{mL}^{-1}$ ). Next, NPs were mixed with buffer solution incubated at $37^{\circ} \mathrm{C}$ and analyzed by DLS. Acdex NPs were measured for $15 \mathrm{~h}$, whereas PLGA NPs were measured over 60 days (see Sect. 2.4). The degradation of the NPs was analyzed by monitoring the change in the mean count rate, size and PDI in DLS.

\subsection{Cell isolation and cell culture}

Leukocyte concentrates were prepared from peripheral blood obtained from healthy human adult donors that received no anti-inflammatory treatment for the last 10 days (Institute of Transfusion Medicine, University Hospital Jena, Germany). The approval for the protocol was given by the ethical committee of the University Hospital Jena and all methods were performed in accordance with the relevant guidelines and regulations. To isolate polymorphonuclear leukocytes (PMNL) and monocytes, the leukocyte concentrates were mixed with dextran (dextran from leuconostoc spp. $M_{W} \sim 40,000 \mathrm{~g} \mathrm{~mol}^{-1}$, Sigma Aldrich, Taufkirchen, Germany) for sedimentation of erythrocytes; the supernatant was centrifuged on lymphocyte separation medium (Histopaque ${ }^{\circledR}-1077$, Sigma Aldrich). Contaminating erythrocytes in the pelleted PMNL were removed by hypotonic lysis using water. The pelleted PMNL were subsequently washed twice in ice-cold phosphate-buffered saline pH 7.4 (PBS) and finally resuspended in PBS. The peripheral blood mononuclear cell (PBMC) fraction on top of lymphocyte separation medium was washed with ice-cold PBS and seeded in cell culture flasks (Greiner Bio-one, Nuertingen, Germany) for $1.5 \mathrm{~h}\left(37^{\circ} \mathrm{C}, 5 \% \mathrm{CO}_{2}\right)$ in PBS with $\mathrm{Ca}^{2+} / \mathrm{Mg}^{2+}\left(0,133 \mathrm{~g} \mathrm{~L}^{-1} / 0,1 \mathrm{~g} \mathrm{~L}^{-1}\right)$ to isolate monocytes by adherence. For differentiation and polarization of monocytes to M1 and M2 macrophages, we followed published procedures [39]. To obtain M1 macrophages, adherent monocytes were treated with $20 \mathrm{ng} \mathrm{mL}^{-1}$ granulocyte macrophage-colony stimulating factor (GM-CSF) Peprotech, Hamburg, Germany) for six days

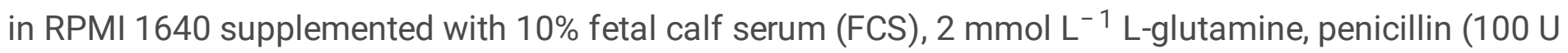
$\left.\mathrm{mL}^{-1}\right)$ and streptomycin $\left(100 \mu \mathrm{g} \mathrm{mL}^{-1}\right)$ for differentiation and were further incubated with $100 \mathrm{ng} \mathrm{mL}^{-1}$ lipopolysaccharide (LPS) and $20 \mathrm{ng} \mathrm{mL}^{-1}$ interferon-y (Peprotech) for $48 \mathrm{~h} . \mathrm{M} 2$ macrophages were obtained by treatment of monocytes with $20 \mathrm{ng} \mathrm{mL}^{1} \mathrm{M}-\mathrm{CSF}$ (Peprotech) for six days, followed by $20 \mathrm{ng}$ $\mathrm{mL}^{-1} \mathrm{IL}-4$ (Peprotech) for $48 \mathrm{~h}$. Correct polarization and purity of macrophages was routinely checked by flow cytometry (FACS Canto Plus flow cytometer, BD Biosciences, Heidelberg, Germany) as reported [45] using the following antibodies: FITC anti-human CD14 ( $2 \mu \mathrm{g} /$ test, clone M5E2, BD Biosciences), PE antihuman CD54 (1 $\mu \mathrm{g} /$ test, clone HA58, BD Biosciences), APC-H7 anti-human CD80 (0.25 $\mu \mathrm{g} / \mathrm{test}$, clone L307.4, BD Biosciences), PE-Cy7 anti-human CD163 (2 $\mu \mathrm{g} /$ test, clone RM3/1, Biolegend, San Diego, CA, USA), PerCP-eFluor710 anti-human CD206 (0.06 $\mu \mathrm{g} /$ test, clone 19.2, BD Biosciences, San Diego, CA, USA). 


\subsection{Determination of 5-LO product formation in PMNL}

For evaluation of the effects on 5-LO product formation in human PMNL, cells $\left(5 \times 10^{6} \mathrm{~mL}^{1}\right)$ were preincubated with BRP-187 or NPs (Acdex[blank], PLGA[blank], Acdex[BRP-187], PLGA[BRP-187]) for the indicated times ( $15 \mathrm{~min}$ up to $5 \mathrm{~h}$ ) at $37^{\circ} \mathrm{C}$. Cells were then stimulated with $\mathrm{Ca}^{2+}$-ionophore $\mathrm{A} 23187$ (Cayman, Ann Arbor, USA) for $10 \mathrm{~min}$, and then the incubation was stopped with $1 \mathrm{~mL}$ ice-cold methanol containing $200 \mathrm{ng} \mathrm{mL}^{1} \mathrm{PGB}_{1}$ as internal standard. Samples were subjected to solid phase extraction and formed 5-LO products were separated and analyzed by RP-HPLC as described [46].

\subsection{Determination of prostaglandin $\mathrm{E}_{2}$ formation in human macrophages}

Human monocyte-derived M1 macrophages $\left(2 \times 10^{6}\right.$ cells) were seeded in 6-well-plates and preincubated for $15 \mathrm{~min}, 5$ or $20 \mathrm{~h}$ with BRP-187 or NPs (Acdex[blank], PLGA[blank], Acdex[BRP-187], PLGA[BRP-187]) at $37^{\circ} \mathrm{C}$. The macrophages were subsequently incubated with pathogenic $\mathrm{E}$. coli [06: $\left.\mathrm{K} 2: \mathrm{H} 1\right]$ for $90 \mathrm{~min}$. The reaction was stopped with ice-cold methanol containing deuterium-labeled internal standards (d8-5SHETE, d4-LTB 4 , d5-LXA 4 , d5-RvD2, and d4-PGE $2 ; 500$ pg each). Samples were kept at $-20{ }^{\circ} \mathrm{C}$ for one day to allow protein precipitation. After centrifugation ( $\left.2000 \mathrm{xg}, 4^{\circ} \mathrm{C}, 10 \mathrm{~min}\right), 8 \mathrm{~mL}$ acidified water was added (final $\mathrm{pH}=3.5$ ) and samples were subjected to solid phase extraction using RP-18 columns and $\mathrm{PGE}_{2}$ was analyzed by UPLC-MS-MS exactly as described before [45].

\subsection{Lactate dehydrogenase assay}

The release of lactate dehydrogenase (LDH) from cells was analyzed using the CytoTox $96 \AA$ NonRadioactive Cytotoxicity Assay (Promega GmbH, Mannheim, Germany). Briefly, $1 \times 10^{6} \mathrm{M} 1$ or M2 macrophages per well, suspended in RPMI-medium containing $10 \%$ FCS, penicillin/streptomycin and Lglutamine, were seeded in a 24-well plate. Lysis control and $0.2 \%$ triton X-100 were added to the cells and incubated for $45 \mathrm{~min}$; compounds and control (0.1\% DMSO) were added and incubated for $24 \mathrm{~h}$ at $37^{\circ} \mathrm{C}$. Stop solution was added, the plate was centrifuged ( $250 \mathrm{x} \mathrm{g}, 4 \mathrm{~min}$, room temperature) and $50 \mu \mathrm{L}$ of supernatant from each well was transferred in a 96-well plate. Afterwards, $50 \mu \mathrm{L}$ of substrate mixture was added and incubated for $30 \mathrm{~min}$ at room temperature in the dark. To finally stop the reaction, $50 \mu \mathrm{L}$ of stop solution were added. The photometric measurement was performed at $490 \mathrm{~nm}$ using a Multiskan Spectrum plate reader (Thermo Fischer).

\subsection{Fluorescence dye-labeled nanoparticle uptake in PMNL}


Time-dependent uptake of fluorescence dye-labeled NPs by PMNL was analyzed by flow cytometry and confocal laser scanning microscopy. Adherent PMNL $\left(2 \times 10^{6}\right)$ were incubated for the indicated time points with $0.5 \mathrm{mg} \mathrm{mL}^{1}$ labeled NPs (PLGA-DY635[BRP-187] or Acdex-RhoB[BRP-187]). For flow cytometry, cells were washed once with PBS containing $0.5 \%$ BSA and incubated with PBA-E (PBS with $0.5 \%$ BSA, 2 mM EDTA and $0.1 \%$ sodium azide) containing $0.4 \%$ lidocaine for detaching. PMNL containing fluorescently stained NPs were analyzed by flow cytometry using BD LSR Fortessa (BD Bioscience). The red laser $(644 \mathrm{~nm})$ in combination with $670 \mid 14$ filters for DY635 labeled NPs and the violet laser ( $405 \mathrm{~nm}$ ) in combination with $655 \mid 8$ filters for rhodamine B labeled NPs were used for flow cytometric analysis. Data were analyzed using FlowJo X Software (BD Bioscience).

For confocal laser scanning microscopy, PMNL were i) washed once with PBS after incubation with the respective NPs for the indicated time points as described above for flow cytometry, ii) submerged with phenol red-free RPMI 1640 and iii) subsequently subjected to microscopic analysis. CLSM images were acquired using a Zeiss LSM 880 (Carl Zeiss, Oberkochen, Germany) with following settings: PLGA NPs labeled with DY635: $\lambda_{\mathrm{Ex}}=633 \mathrm{~nm}, \lambda_{\mathrm{Em}}=638$ to $759 \mathrm{~nm}$ and transmission signal with PMT detector; Acdex NPs labeled with rhodamine B: $\lambda_{\mathrm{Ex}}=514 \mathrm{~nm}, \lambda_{\mathrm{Em}}=531$ to $703 \mathrm{~nm}$ and transmission signal with PMT detector. Images were captured with an iLCI Plan-Neofluar $63 \times$ objective using identical settings for image acquisition within experimental groups.

\section{Abbreviations}

5-LO 5-Lipooxygenase

5S-HETE 5-Hydroxyeicosatetraenoic acid

AA Arachidonic acid

Acdex Acetalated dextran

Acdex-RhodB Acetalated dextran coupled to Rhodamine B

BSA Bovine serum albumin

CLSM Confocal laser scanning microscopy

cox Cyclooxygenase

$\mathrm{d}_{\mathrm{H}} \quad$ Hydrodynamic diameter

DLS Dynamic light scattering

DMAc Dimethylacetamide

DMF Dimethylformamide 


\begin{tabular}{|c|c|}
\hline DMSO & Dimethylsulfoxide \\
\hline EDC & 1-Ethyl-3-(3-dimethylaminopropyl)carbodiimide \\
\hline EDTA & Ethylenediaminetetraacetic acid \\
\hline $\mathrm{EE}$ & Encapsulation efficiency \\
\hline FCS & Fetal calf serum \\
\hline FLAP & 5-Lipoxygenase-activating protein \\
\hline GM-CSF & Granulocyte macrophage-colony stimulating factor \\
\hline $\mathrm{IC}_{50}$ & Half maximal inhibitory concentration \\
\hline $\begin{array}{l}\mathrm{ICH} \\
\text { human use }\end{array}$ & International council for harmonization of technical requirements for pharmaceuticals for \\
\hline IL-4 & Interleukin 4 \\
\hline LC & Loading capacity \\
\hline LDH & Lactate dehydrogenase \\
\hline LT & Leukotrienes \\
\hline $\mathrm{LTB}_{4}$ & Leukotriene $\mathrm{B}_{4}$ \\
\hline LXA4 & Lipoxin $\mathrm{A}_{4}$ \\
\hline MFI & Mean fluorescence intensity \\
\hline mPGES-1 & Microsomal prostaglandin $E_{2}$ synthase- 1 \\
\hline MTT & 3-(4,5-Dimethylthiazol-2-yl)-2,5-diphenyltetrazolium bromide \\
\hline $\mathrm{NHs}$ & $N$-hydroxysuccinimide \\
\hline NPs & Nanoparticles \\
\hline NSAIDs & Nonsteroidal anti-inflamamtory drugs \\
\hline PBA-E & PBS with $0.5 \%$ BSA, 2 mM EDTA and $0.1 \%$ sodium azide \\
\hline PBMC & Peripheral blood mononuclear cell \\
\hline
\end{tabular}




$\begin{array}{ll}\text { PBS } & \text { Phosphate buffer saline } \\ \text { PDI } & \text { Polydispersity index } \\ \text { PG } & \text { Prostaglandins } \\ \text { PGB }_{1} & \text { Prostaglandin } \mathrm{B}_{1} \\ \text { PGE }_{2} & \quad \text { Prostaglandin } \mathrm{E}_{2} \\ \text { PGH }_{2} & \quad \text { Prostaglandin } \mathrm{H}_{2} \\ \text { PLGA } & \text { Poly(lactic-co-glycolic) acid } \\ \text { PMNL } & \text { Polymorphonuclear leukocytes } \\ \text { PVA } & \text { Poly(vinyl alcohol) } \\ \text { RP-HPLC } & \text { Reverse phase-high performance liquid chromatography } \\ \text { RvD2 } & \text { Resolvin D2 } \\ \text { SEM } & \text { Scanning electron microscope } \\ \text { SPE } & \text { Solid phase extraction } \\ \text { TEA } & \text { Triethylamine } \\ \text { THF } & \text { Tetrahydrofuran }\end{array}$

UPLC-MS/MS Ultra performance liquid chromatography tandem mass spectrometry

\section{Declarations}

\subsection{Ethics approval and consent to participate}

The experimental protocol was approved by the ethical committee of the University Hospital Jena (No. 5050-01/17). All methods were performed in accordance with the relevant guidelines and regulations.

\subsection{Consent for publication}

Not applicable. 


\subsection{Availability of data and materials}

Not applicable.

\subsection{Competing interest}

The authors declare that they have no competing interests.

\subsection{Funding}

This work was supported by the Deutsche Forschungsgemeinschaft (DFG), Collaborative Research Center SFB 1278 "PolyTarget", projects A04, C01 and Z01. The SEM facilities of the Jena Center for Soft Matter (JCSM) were also established with a grant from the DFG. The LSM880 ELYRA PS.1 was funded with a grant from the DFG.

\subsection{Author contribution}

BSP, CK, PMJ, DP, MW and SS performed the experiments. BSP and CK wrote the manuscript. PK synthesized Acdex. EB synthesized BRP-187. BSP produced the nanoparticles. MW and SL did further characterization of NPs. SH supervised the electron micoscropy. AK supervised the UPLC MS/MS analysis. AV, StS and OW made critical revision and corrected the manuscript. AV, StS, OW and US designed the research and supervised the work. All authors read and approved the final manuscript.

\subsection{Acknowledgments}

This work was supported by the Deutsche Forschungsgemeinschaft (DFG), Collaborative Research Center SFB 1278 "PolyTarget", projects A04, C01 and Z01. The SEM facilities of the Jena Center for Soft Matter (JCSM) were also established with a grant from the DFG. The LSM880 ELYRA PS.1 was funded with a grant from the DFG. The authors also want to thank PD Dr. Christoph Enzensperger from SmartDyeLivery $\mathrm{GmbH}$ for the preparation of PLGA-DY635 polymer, as well as Bärbel Beringer-Siemers and Benjamin Schenz for technical support.

\section{References}

1. Medzhitov R. Inflammation 2010: New adventures of an old flame. Cell. 2010;771-6.

2. Funk CD. Prostaglandins and leukotrienes: Advances in eicosanoid biology. Science. 2001;1871-5.

3. Samuelsson B, Morgenstern R, Jakobsson P. Membrane prostaglandin E synthase-1: A novel therapeutic target. Pharmacol Rev. 2007;207-24. 
4. Grosser T, Fries S, Fitzgerald GA. Biological basis for the cardiovascular consequences of COX-2 inhibition: Therapeutic challenges and opportunities. J Clin Invest. 2006;4-15.

5. Rådmark 0 , Werz 0 , Steinhilber D, Samuelsson B. 5-Lipoxygenase, a key enzyme for leukotriene biosynthesis in health and disease. Biochim Biophys Acta - Mol Cell Biol Lipids. 2015;331-9.

6. Werz O, Gerstmeier J, Garscha U. Novel leukotriene biosynthesis inhibitors (2012-2016) as antiinflammatory agents. Expert Opin Ther Pat. 2017;607-20.

7. Garscha U, Voelker S, Pace S, Gerstmeier J, Emini B, Liening S, et al. BRP-187: A potent inhibitor of leukotriene biosynthesis that acts through impeding the dynamic 5-lipoxygenase/5-lipoxygenaseactivating protein (FLAP) complex assembly. Biochem Pharmacol. 2016;17-26.

8. Koeberle A, Werz O. Natural products as inhibitors of prostaglandin E2 and pro-inflammatory 5lipoxygenase-derived lipid mediator biosynthesis. Biotechnol Adv. 2018;1709-23.

9. Suarez S, Grover GN, Braden RL, Christman KL, Almutairi A. Tunable protein release from acetalated dextran microparticles: A platform for delivery of protein therapeutics to the heart post-MI. Biomacromolecules. 2013;3927-35.

10. Shkodra-Pula B, Grune C, Traeger A, Vollrath A, Schubert S, Fischer D, et al. Effect of surfactant on the size and stability of PLGA nanoparticles encapsulating a protein kinase $C$ inhibitor. Int J Pharm. 2019;756-64.

11. Choi YH, Han HK. Nanomedicines: Current status and future perspectives in aspect of drug delivery and pharmacokinetics. J. Pharm. Investig. 2018. p. 43-60.

12. Avgoustakis K. Polylactic-co-glycolic acid (PLGA). In: Wnek GE, Bowlin GL, editors. Encycl Biomater Biomed Eng. 2008. p. 2259-69.

13. Wang Y, Qu W, Choi SH. FDA's regulatory science program for generic PLA/ PLGA-based drug products. Am. Pharm. Rev. 2016.

14. Danhier F, Ansorena E, Silva JM, Coco R, Le Breton A, Préat V. PLGA-based nanoparticles: An overview of biomedical applications. J Control Release. 2012;505-22.

15. Swider E, Koshkina O, Tel J, Cruz LJ, de Vries IJM, Srinivas M. Customizing poly(lactic-co-glycolic acid) particles for biomedical applications. Acta Biomater. 2018;38-51.

16. Gentile P, Chiono V, Carmagnola I, Hatton P V. An overview of poly(lactic-co-glycolic) acid (PLGA)based biomaterials for bone tissue engineering. Int J Mol Sci. 2014;3640-59.

17. Bachelder EM, Pino EN, Ainslie KM. Acetalated dextran: A tunable and acid-labile biopolymer with facile synthesis and a range of applications. Chem Rev. 2017;1915-26.

18. Wang Z, Gupta SK, Meenach SA. Development and physicochemical characterization of acetalated dextran aerosol particle systems for deep lung delivery. Int J Pharm. 2017;264-74.

19. Bachelder EM, Beaudette TT, Broaders KE, Dashe J, Fréchet JMJ. Acetal-derivatized dextran: An acidresponsive biodegradable material for therapeutic applications. J Am Chem Soc. 2008;10494-5.

20. Braga CB, Perli G, Becher TB, Ornelas C. Biodegradable and pH-responsive acetalated dextran (ACDex) nanoparticles for NIR imaging and controlled delivery of a platinum-based prodrug into cancer 
cells. Mol Pharm. 2019;2083-94.

21. Schubert S, Delaney, Jr JT, Schubert US. Nanoprecipitation and nanoformulation of polymers: From history to powerful possibilities beyond poly(lactic acid). Soft Matter. 2011;1581-8.

22. European Medicines Agency. ICH guideline Q3C (R6) on impurities: Guideline for residual solvents. 2019. https://www.ema.europa.eu/en/documents/scientific-guideline/international-conferenceharmonisation-technical-requirements-registration-pharmaceuticals-human-use_en-33.pdf. Accessed 26 Feb 2020.

23. Yu Y, Tan S, Zhao S, Zhuang X, Song Q, Wang Y, et al. Antitumor activity of docetaxel-loaded polymeric nanoparticles fabricated by Shirasu porous glass membrane-emulsification technique. Int J Nanomedicine. 2013;2641-52.

24. Wang Y, Li P, Truong-Dinh Tran T, Zhang J, Kong L. Manufacturing techniques and surface engineering of polymer based nanoparticles for targeted drug delivery to cancer. Nanomaterials. 2016;26.

25. Perevyazko I, Vollrath A, Hornig S, Pavlov GM, Schubert US. Characterization of poly(methyl methacrylate) nanoparticles prepared by nanoprecipitation using analytical ultracentrifugation, dynamic light scattering, and scanning electron microscopy. J Polym Sci Part A Polym Chem. 2010;3924-31.

26. Dhakar RC, Maurya SD, Sagar BPS, Bhagat S, Kumar PS, Jain CP. Variables influencing the drug entrapment efficiency of microspheres: A pharmaceutical review. Der Pharm Lett. 2010;102-16.

27. Singh R, Lillard JW. Nanoparticle-based targeted drug delivery. Exp Mol Pathol. 2009;215-23.

28. Cheng J, Teply BA, Sherifı I, Sung J, Luther G, Gu FX, et al. Formulation of functionalized PLGA-PEG nanoparticles for in vivo targeted drug delivery. Biomaterials. 2007;869-76.

29. Manual: Zetasizer Nano User Manual (Man0485-1.1). https://fdocuments.in/document/manualzetasizer-nano-user-manual-man0485-11.html. Accessed 26 Feb 2020.

30. Karavelidis V, Karavas E, Giliopoulos D, Papadimitriou S, Bikiaris D. Evaluating the effects of crystallinity in new biocompatible polyester nanocarriers on drug release behavior. Int $\mathrm{J}$ Nanomedicine. 2011;3021-32.

31. Holy CE, Dang SM, Davies JE, Shoichet MS. In vitro degradation of a novel poly(lactide-co-glycolide) 75/25 foam. Biomaterials. 1999;1177-85.

32. Martins C, Sousa F, Araújo F, Sarmento B. Functionalizing PLGA and PLGA derivatives for drug delivery and tissue regeneration applications. Adv Healthc Mater. 2018;1701035.

33. Engineer C, Parikh J, Raval A. Hydrolytic degradation behavior of $50 / 50$ poly lactide-co-glycolide from drug eluting stents. Trends Biomater Artif Organs. 2010;131-8.

34. Evonik. RESOMER® controlled release polymers. 2019.

https://healthcare.evonik.com/product/healthcare/en/products/biomaterials/resomer/pages/controlled-release.aspx. Accessed 15 Aug 2019. 
35. Karavelidis V, Giliopoulos D, Karavas E, Bikiaris D. Nanoencapsulation of a water soluble drug in biocompatible polyesters. Effect of polyesters melting point and glass transition temperature on drug release behavior. Eur J Pharm Sci. 2010;636-43.

36. Englert C, Brendel JC, Majdanski TC, Yildirim T, Schubert S, Gottschaldt M, et al. Pharmapolymers in the 21st century: Synthetic polymers in drug delivery applications. Prog Polym Sci. 2018;107-64.

37. Lee SC, Oh JT, Jang MH, Chung S II. Quantitative analysis of polyvinyl alcohol on the surface of poly(D,L-lactide-co-glycolide) microparticles prepared by solvent evaporation method: Effect of particle size and PVA concentration. J Control Release. 1999;123-32.

38. Surette ME. Lipopolysaccharides prime whole human blood and isolated neutrophils for the increased synthesis of 5-lipoxygenase products by enhancing arachidonic acid availability: Involvement of the CD14 antigen. J Exp Med. 1993;1347-55.

39. Werz O, Gerstmeier J, Libreros S, De La Rosa X, Werner M, Norris PC, et al. Human macrophages differentially produce specific resolvin or leukotriene signals that depend on bacterial pathogenicity. Nat Commun. 2018;1-12.

40. Mosca M, Polentarutti N, Mangano G, Apicella C, Doni A, Mancini F, et al. Regulation of the microsomal prostaglandin E synthase-1 in polarized mononuclear phagocytes and its constitutive expression in neutrophils. J Leukoc Biol. 2007;320-6.

41. Koeberle A, Werz O. Perspective of microsomal prostaglandin E2 synthase-1 as drug target in inflammation-related disorders. Biochem Pharmacol. 2015;1-15.

42. Banoglu E, Çelikoğlu E, Völker S, Olgaç A, Gerstmeier J, Garscha U, et al. 4,5-Diarylisoxazol-3carboxylic acids: A new class of leukotriene biosynthesis inhibitors potentially targeting 5lipoxygenase-activating protein (FLAP). Eur J Med Chem. 2016;1-10.

43. Hennig D, Schubert S, Dargatz H, Kostenis E, Fahr A, Schubert US, et al. Novel insights into appropriate encapsulation methods for bioactive compounds into polymers: A study with peptides and HDAC inhibitors. Macromol Biosci. 2014;69-80.

44. Spek S, Haeuser M, Schaefer MM, Langer K. Characterisation of PEGylated PLGA nanoparticles comparing the nanoparticle bulk to the particle surface using UV-VIS spectroscopy, SEC, $1 \mathrm{H}-\mathrm{NMR}$ spectroscopy, and X-ray photoelectron spectroscopy. Appl Surf Sci. 2015;378-85.

45. Werner M, Jordan PM, Romp E, Czapka A, Rao Z, Kretzer C, et al. Targeting biosynthetic networks of the proinflammatory and proresolving lipid metabolome. FASEB J. 2019;6140-53.

46. Werz O, Bürkert E, Samuelsson B, Rådmark O, Steinhilber D. Activation of 5-lipoxygenase by cell stress is calcium independent in human polymorphonuclear leukocytes. Blood. 2002;1044-52.

\section{Figures}



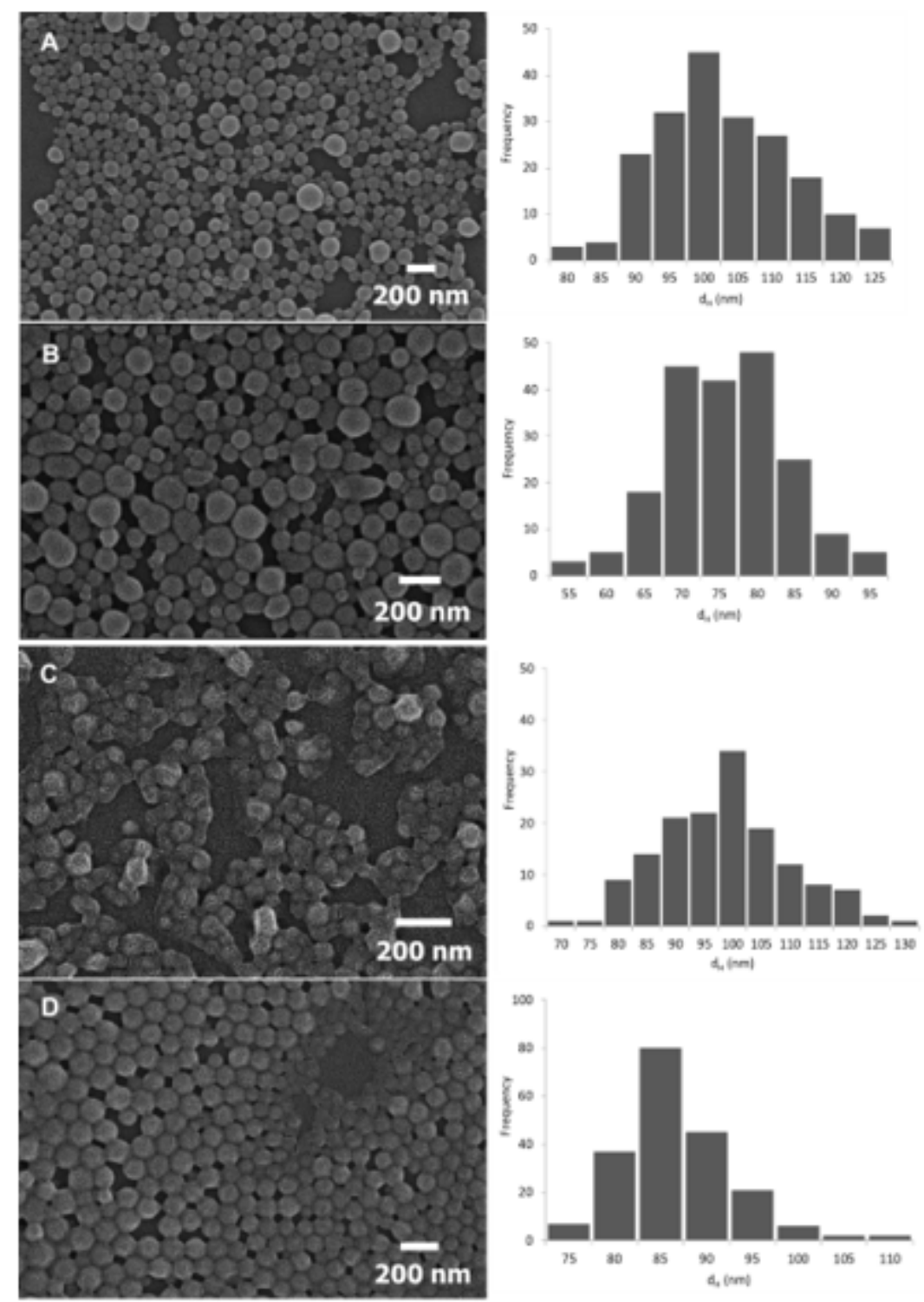

Figure 1

SEM images of NPs: Acdex (A), Acdex[BRP-187] (B), PLGA (C), PLGA[BRP-187] (D). 
Count rate

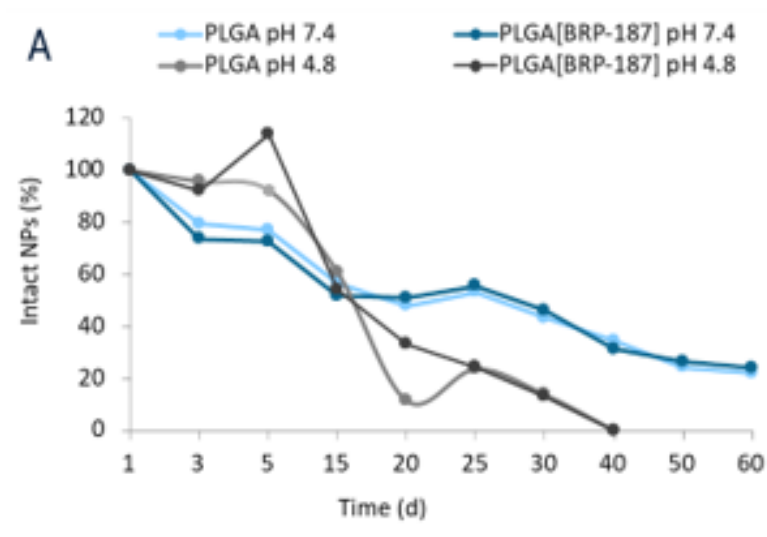

Count rate

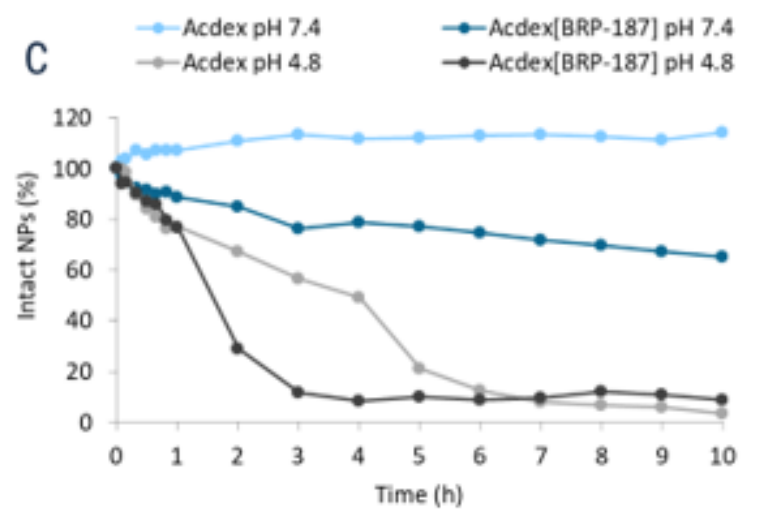

Size and PDI

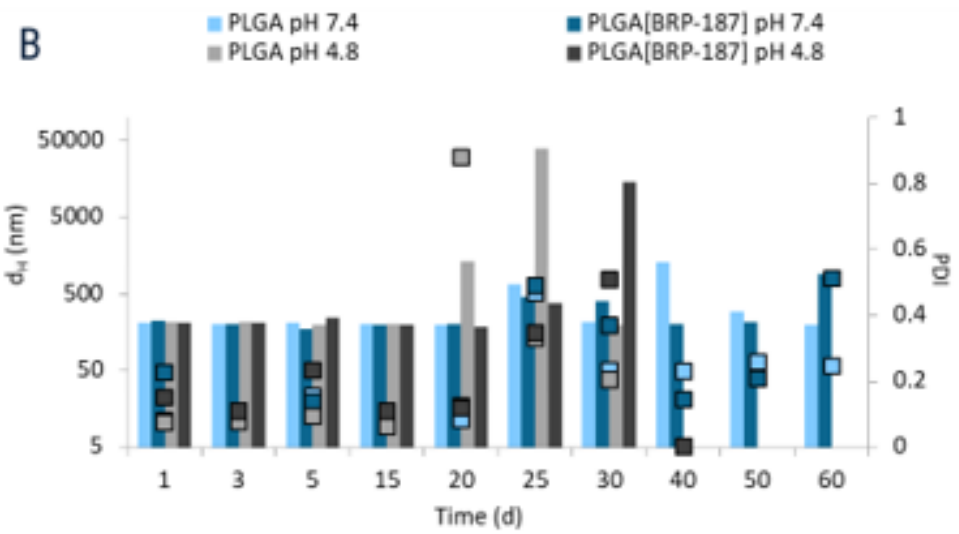

Size and PDI

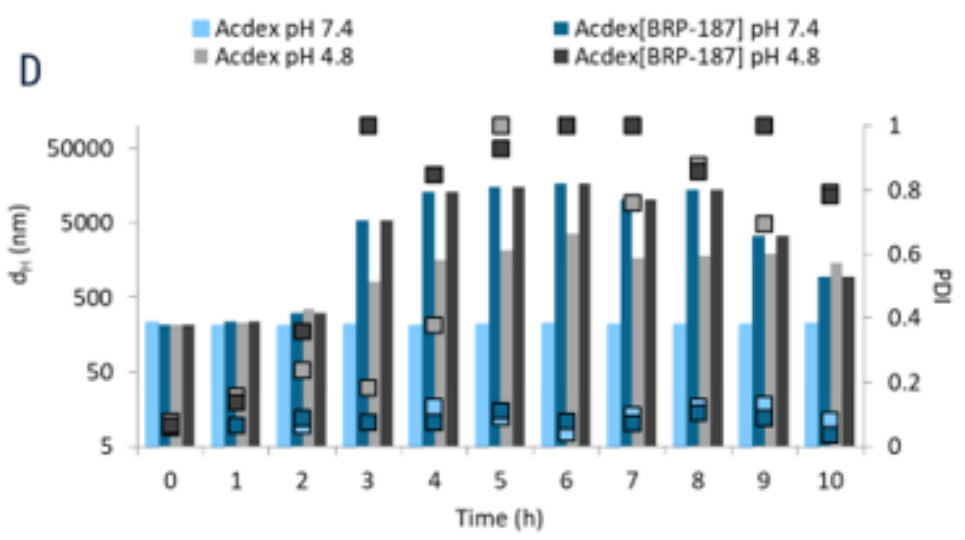

Figure 2

Degradation of NPs at physiological (7.4) and acidic (4.8) pH values: Acdex and Acdex[BRP-187] (A, B); and PLGA and PLGA[BRP-187] (C, D) measured by DLS $(n=1)$.
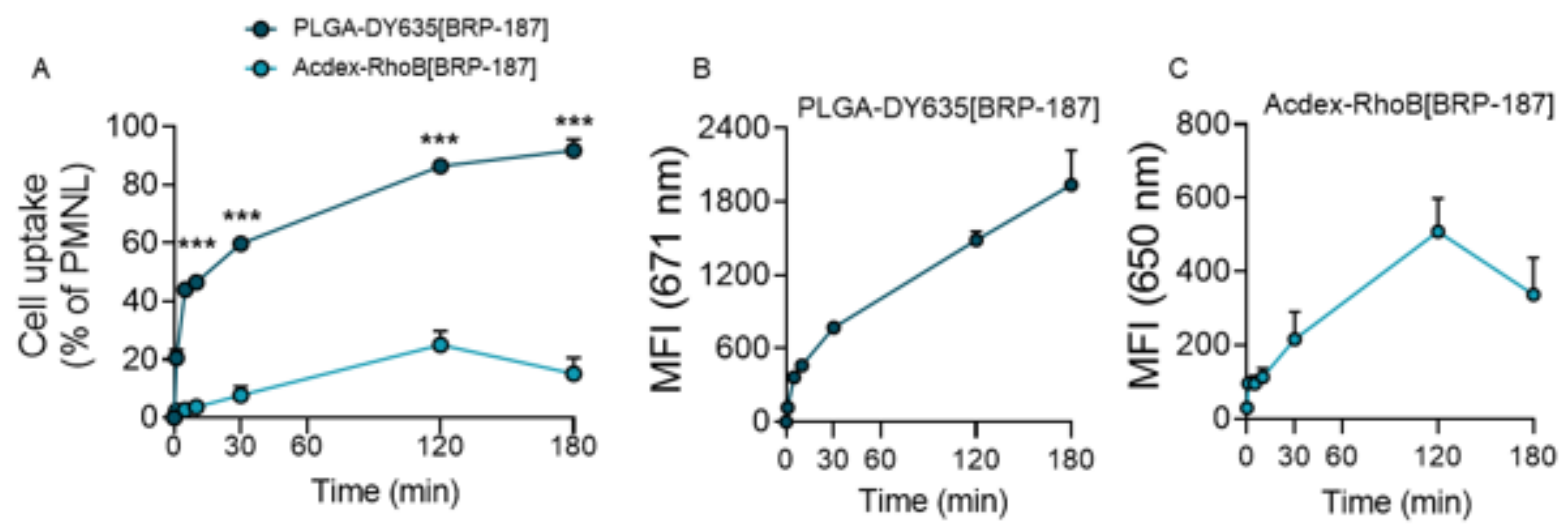

\section{Figure 3}

PMNL $(1 \times 106)$ were incubated with 0.5 mg mL-1 PLGA-DY635[BRP-187] or Acdex-RhoB[BRP-187] NPs for the indicated time points at $37^{\circ} \mathrm{C}$. (A) Percentage of PMNL gated as positive due to the fluorescence signal of the dye-labeled NPs in the cell. (B, C) Mean fluorescence intensity (MFI) of NPs in the cell, 
measured by flow cytometry. For statistics analysis, a multiple t-test was used; $p<0.05(*) ; p<0.01(* *)$; $\mathrm{p}<0.001(* * *) ; n=4$.
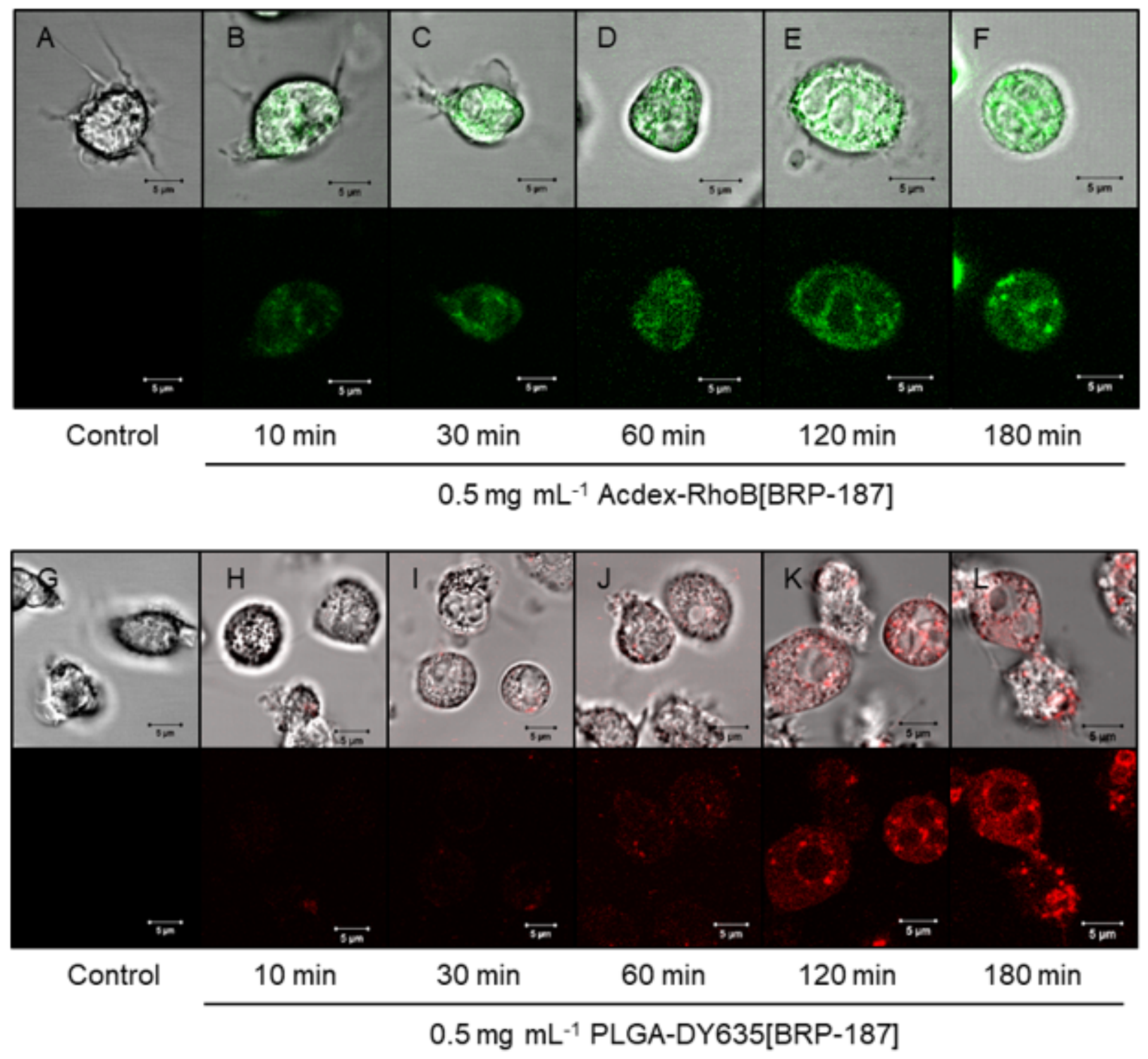

Figure 4

Confocal laser scanning microscopy of PMNL after isolation (A, G) and incubation at $37^{\circ} \mathrm{C}$ with NPs for the indicated timepoints (B-F and $\mathrm{H}-\mathrm{L})$. Micrographs in the upper rows display the individual fluorescence channel while images in the bottom rows display the additional overlay of the transmitted light channel. 

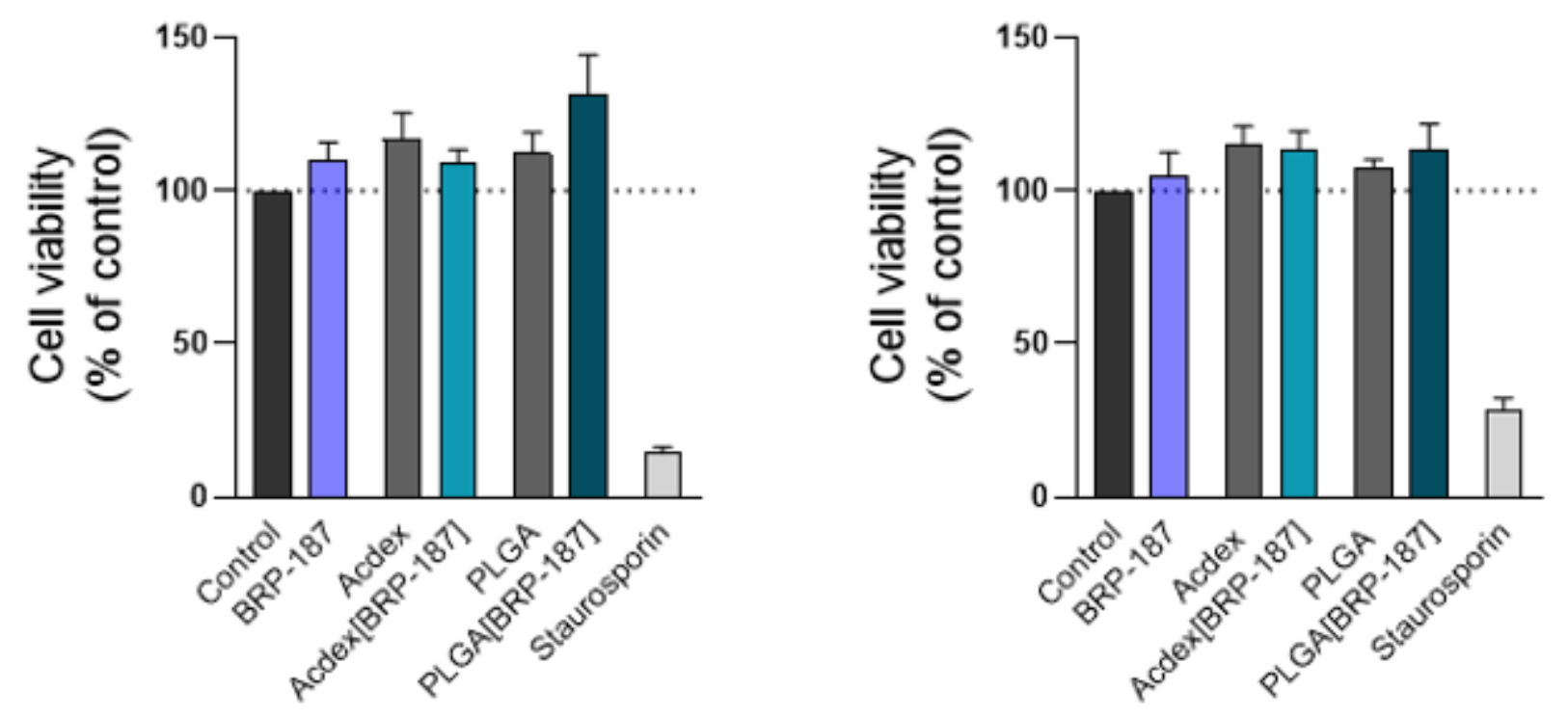

Figure 5

M1 macrophages (A) or M2 macrophages (B) were incubated with control (0.1\% DMSO), free BRP-187 $(10 \mu \mathrm{M})$, NP without drug, BRP-187 $(10 \mu \mathrm{M})$ encapsulated into NP, or positive control (staurosporin $3 \mu \mathrm{M})$ for $24 \mathrm{~h}$. Then, the release of LDH was analyzed using the Promega Cytotox $96 \AA$ assay. Values are normalized to the DMSO control (100\%) and given as percentage of cell viability; data are means + S.E.M., $n=3$.
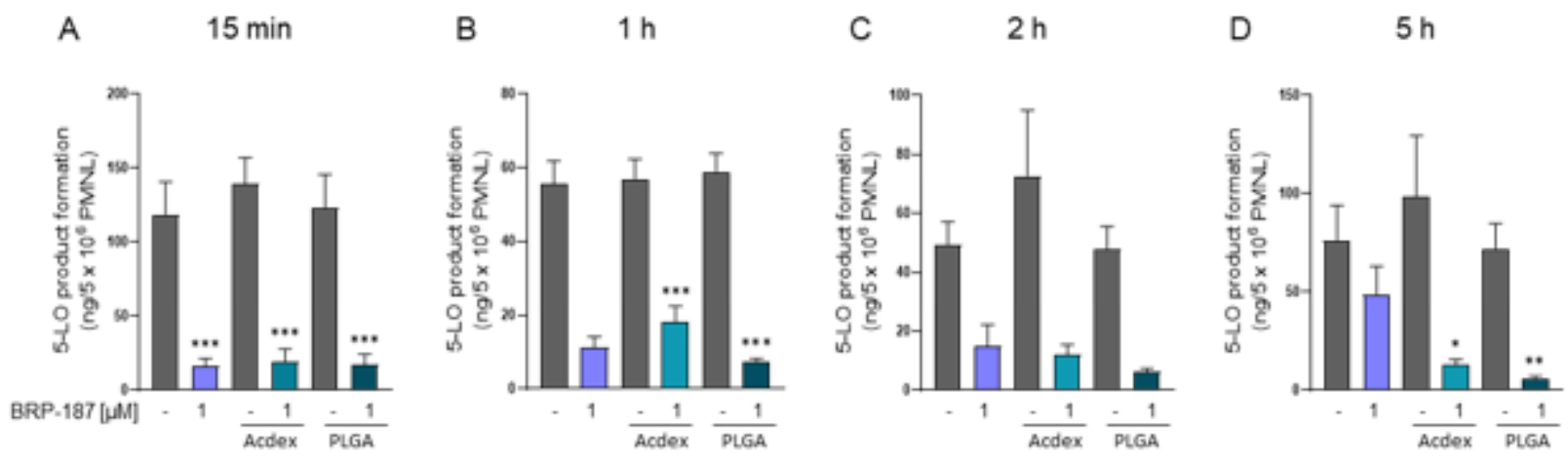

\section{Figure 6}

PMNL (5 x 106) were preincubated with control (0.1\% DMSO), BRP-187, Acdex, PLGA, Acdex[BRP-187] and PLGA[BRP-187] NPs for the indicated time points at $37^{\circ} \mathrm{C}$. The cells were then stimulated with 2.5 $\mathrm{M}$ A23187 for $10 \mathrm{~min}$, and 5-LO product formation was analyzed. Values are given as ng of 5-LO products (sum of the trans-isomers of leukotriene B4 (LTB4), LTB4 and 5-hydroxyeicosatetraenoic acid (5HETE)). For statistical analysis, one-way ANOVA and Tukey's multi comparison test was performed. $p<0.05(*) ; p<0.01(* *) ; p<0.001(* * *) ; n=4$. 
A

15 min

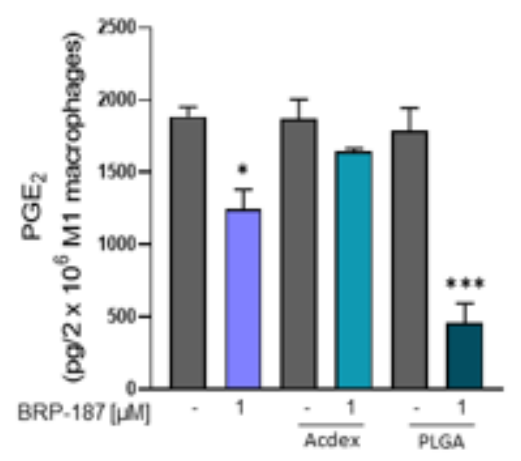

B

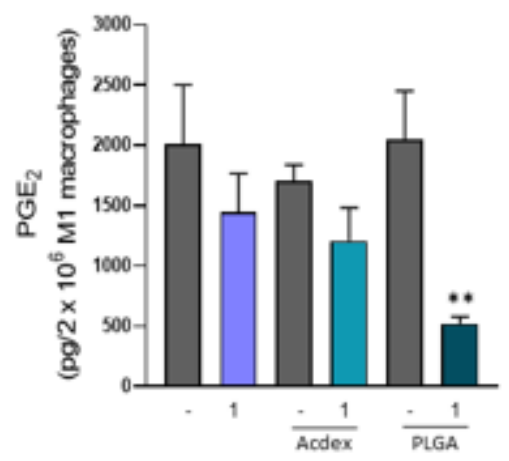

C

$20 \mathrm{~h}$

\section{Figure 7}

Determination of PGE2 formation in human macrophages: M1 macrophages $(2 \times 106)$ were preincubated with BRP-187 or with BRP-187 encapsulated into Acdex or PLGA NPs for the indicated timepoints at 37 ${ }^{\circ} \mathrm{C}$. Cells were then exposed to $\mathrm{E}$. coli $(\mathrm{O6}: \mathrm{K} 2: \mathrm{H} 1), \mathrm{MOI}=50$. After 90 min at $37^{\circ} \mathrm{C}$ the reaction was stopped and PGE2 was analyzed after solid phase extraction (SPE) by UPLC-MS/MS. Values are given as pg of PGE2 per $2 \times 106$ M1. For statistical analysis one-way ANOVA $(p<0.0001)$ and a Tukey's multi comparison test was performed. $p<0.05(*) ; p<0.01(* \star) ; p<0.001(\star \star \star) ; n=3-4$. 